THE ROLE OF RARE-EARTH DOPANTS IN NANOPHASE ZIRCONIA

CATALYSTS FOR AUTOMOTIVE EMISSION CONTROL*

\author{
C.-K. Loong ${ }^{1}$ and M. Ozawa ${ }^{2}$ \\ ${ }^{1}$ Argonne National Laboratory, Argonne, IL 60439-4814, USA \\ ${ }^{2}$ Nagoya Institute of Technology, Tajimi, 507-0071, Japan \\ The submitted manuscript has been created by the University \\ Chicago as Operator of Argonne National Laboratory ("Argonne") \\ under Contractor No. W-31-109-ENG-38 with the U.S. Department \\ of Energy. The U.S. Government retains for itself, and others acting \\ on its behalf, a paid-up, nonexclusive, irrevocable worldwide license \\ in said article to reproduce, prepare derivative works, distribute \\ copies to the public, and perform publicly and display publicly, by or \\ on behalf of Government.
}

An invited paper to be presented at the $22^{\text {nd }}$ Rare Earth Research Conference Argonne National Laboratory, July 10-15, 1999

To be published in Journal of Alloys and Compounds

*Work supported by U. S. Department of Energy, BES, contract No. W-31-109-ENG-38

Corresponding author:

Chun Loong

IPNS, Bldg. 360

Argonne National laboratory

9700 S. Cass Ave

Argonne, IL 60439-4814

U.S. A.

Tel: $630-252-5596$

FAX: 630-252-4163

Email: ckloong@ anl.gov

The submitted manuscript has been created
by the University of Chicago as Operator of
Argonne National Laboratory ("Argonne")
under Contract No. W-31-109-ENG-38 with
the U.S. Department of Energy. The U.S.
Government retains for itself, and others act-
ing on its behalf. a paid-up, nonexclusive,
irrevocable worldwide license in said article
to reproduce, prepare derivative works, dis-
tribute copies to the public, and pertorm pub-
licly and display publicly, by or on behal: of
the Government. 


\section{DISCLAIMER}

This report was prepared as an account of work sponsored by an agency of the United States Government. Neither the United States Government nor any agency thereof, nor any of their employees, make any warranty, express or implied, or assumes any legal liability or responsibility for the accuracy, completeness, or usefuiness of any information, apparatus, product, or process disclosed, or represents that its use would not infringe privately owned rights. Reference herein to any specific commercial product, process, or service by trade name, trademark, manufacturer, or otherwise does not necessarily constitute or imply its endorsement, recommendation, or favoring by the United States Government or any agency thereof. The views and opinions of authors expressed herein do not necessarily state or reflect those of the United States Government or any agency thereof. 


\section{DISCLAIMER}

Portions of this document may be illegible in electronic image products. Images are produced from the best available original document. 


\title{
THE ROLE OF RARE-EARTH DOPANTS IN NANOPHASE ZIRCONIA CATALYSTS FOR AUTOMOTIVE EMISSION CONTROL
}

\author{
C.-K. Loong ${ }^{1}$ and M. Ozawa ${ }^{2}$ \\ ${ }^{1}$ Argonne National Laboratory, Argonne, IL 60439-4814, USA \\ ${ }^{2}$ Nagoya Institute of Technology, Tajimi, 507-0071, Japan
}

Rare earth (RE) modification of automotive catalysts (e.g., $\mathrm{ZrO}_{2}$ ) for exhaust gas treatment results in outstanding improvement of the structural stability, catalytic functions and resistance to sintering at high temperatures. Owing to the low redox potential of nonstoichiometric $\mathrm{CeO}_{2}$, oxygen release and intake associated with the conversion between the $3+$ and $4+$ oxidation states of the $\mathrm{Ce}$ ions in Ce-doped $\mathrm{ZrO}_{2}$ provide the oxygen storage capacity that is essentially to effective catalytic functions under dynamic air-to-fuel ratio cycling. Doping tripositive RE ions such as $\mathrm{La}$ and $\mathrm{Nd}$ in $\mathrm{ZrO}_{2}$, on the other hand, introduces oxygen vacancies that affect the electronic and ionic conductivity. These effects, in conjunction with the nanostructure and surface reactivity of the fine powders, present a challenging problem in the development of better $\mathrm{ZrO}_{2}$-containing three-way catalysts. We have carried out in-situ small-to-wide angle neutron diffraction at high temperatures and under controlled atmospheres to study the structural phase transitions, sintering behavior, and $\mathrm{Ce}^{3+} \leftrightarrow \mathrm{Ce}^{4+}$ redox process. We found substantial effects due to RE doping on the nature of aggregation of nanoparticles, defect formation, crystal phase transformation, and metal-support interaction in $\mathrm{ZrO}_{2}$ catalysts for automotive emission control. 


\section{Introduction: A new challenge in materials research for better autocatalysts}

Concern regarding the grave consequences of excessive emission of greenhouse gases and other pollutants has risen to a global level with multiple impacts on modern societies. Automotive exhaust is identified as one of the major sources of air pollution. In response to popular awareness, governments, led by the United States, the European Community and Japan are imposing strict regulatory policies of standards on automotive emission. Current federal standards require a vehicle emission of hydrocarbon (HC)/CO/NOx less than $0.31 / 4.2 / 0.6 \mathrm{~g} / \mathrm{mi}$ with a durability of $100,000 / 10$ mileage/year. In 2004 a more severe standard $(0.125 / 1.7 / 0.2 \mathrm{~g} / \mathrm{mi})$ will be enforced. California State laws call for an even stringent control.[1] Although the threeway catalytic converter for automobiles was celebrated as one of the most successful anti-airpollution devices in the twentieth century, the new requirement of the "ultralow emission vehicles" will demand a performance level of the conventional TWC going beyond its current capability. In addition, the imposition of limited $\mathrm{CO}_{2}$ emissions requires a shift of the air-to-fuel ratio (A/F) to the "lean-burn" condition, which the current TWCs are unable to adequately remove the pollutants, particularly NOx. Consequently, high-performance three-way catalysts (TWCs) for purification of automotive exhaust are in great demand. The development of durable, high-activity, and versatile TWCs has become a pressing issue in governmental and industrial research.

Common TWCs consist of precious metals (e.g., platinum, palladium and rhodium), supports (e.g., transition aluminas) and promoters (e.g., rare-earth oxides and zirconia). Cerium dioxide $\left(\mathrm{CeO}_{2}\right)$ is one of the most important promoters in TWC for its ability in enhancing the removal 
of carbon monoxide (CO), hydrocarbon ( $\mathrm{HC}$ ) and nitrogen-oxide (NOx) pollutants. $[2,3]$ The oxide promoters of trivalent $\mathrm{RE}$ including $\mathrm{La}$ and $\mathrm{Nd}$ effect better NOx-CO oxidation on precious metals. $\mathrm{ZrO}_{2}$ stabilized by $\mathrm{CeO}_{2}$ and other $\mathrm{RE}$ is know to increase durability and removal efficiency. Optimization of the parameters in the composition and structure of these oxides in conjunction with application of precious metals has lead to the high performance of modern TWCs.

While traditional experimental methods such as thermal analysis, temperature-programmed desorption measurements, microscopy and chemical probes are useful, microscopic investigations at nanometer resolution of the structural and dynamic properties of catalysts in an environment that simulates operational conditions have become important. X-ray and neutron studies can in principle provide new information on several key issues, such as: (a) the microscopic structure of heterogeneous catalysts in terms of atomic positions and formation of vacancies or defects in non-stoichiometric and dopant-modified materials; (b) the surface chemistry involving the adsorption and desorption of molecules; (c) the kinetics of redox reactions of ceria in TWCs under dynamic A/F fluctuations; and (d) the evolution of microstructure (e.g., phase transformations, atomic diffusion, aggregate and sintering of particles, etc.) in practical catalysts during operation cycles. In this paper we report recent neutron studies of a series of rare-earth doped zirconia TWCs, with emphasis on the role of rare-earth elements in promoting catalytic reactions through structural modification. The future trend of in-situ scattering experiments using neutrons and $\mathrm{x}$-rays for the characterization of rare-earth containing catalysts will also be discussed. 


\section{Effects of rare-earth (RE) doping on the microstructure of a powder}

Control of the microstructure in powders (e.g., aggregation of crystallites, pore morphology) is one the important areas in materials research. Ultrafine zirconia powders are commonly prepared by hydrolysis of a zirconyl salt such as $\mathrm{ZrOCl} \cdot 8 \mathrm{H}_{2} \mathrm{O}$. The aqueous solution is treated by combined steps involving heating, aging, and $\mathrm{pH}$ control until a hydrous zirconia gel is produced either from precipitation or centrifugation.[4] The zirconia powder is obtained by filtering, washing and calcining the gel. Despite of numerous studies, the hydrolysis, complexation, and precipitation of the cationic species are not fully understood. It is thought that initially tetramers of $\left[\mathrm{Zr}_{4}(\mathrm{OH})_{8} \cdot 16\left(\mathrm{H}_{2} \mathrm{O}\right)\right]^{8+}$, each of which consists of a square planar array of four $\mathrm{Zr}$ cations bridged by $\mathrm{OH}$ ions and surrounded by $\mathrm{H}_{2} \mathrm{O}$ molecules, are formed in the solution.[5] Under appropriate conditions upon heating or $\mathrm{pH}$ adjustment, the tetramers interact to form initially octamers and then higher order complexes that may involve two-dimensional sheets before the eventual precipitation of three-dimensional structure.[6] Previous small-angle $\mathrm{x}$-ray scattering (SAXS) provided evidence of the formation of tetramers, octamers and high-order complexes.[7] The rare-earth modified zirconias of the present study were prepared by a coprecipitation technique from a $\mathrm{ZrOCl}_{2}$ and $\mathrm{RECl}_{3}$ solution. [4] Since $\mathrm{RE}$ differs from $\mathrm{Zr}$ in the ionic size and/or charges, the microstructure of the RE-modified powder is expected to be different from that of pure zirconia.

Small-angle neutron scattering (SANS) enables the characterization of the microstructure in terms of primary-particle size, surface area, porosity, and nature of aggregation over a length scale of $\sim 1$ to $100 \mathrm{~nm}$. Fig. 1 shows the $S A N S$ profiles (log-Intensity versus $\log -\mathrm{Q}$ where $\mathrm{Q}$ is the neutron 
wavevector) of the $10 \mathrm{~mol} \% \mathrm{RE}$-doped zirconia $(\mathrm{RE}=\mathrm{Ce}$ and $\mathrm{Nd})$ and the pure zirconia. All the powders were annealed at $600^{\circ} \mathrm{C}$ in air for $\sim 3 \mathrm{~h}$. The intensity profiles of the three samples show distinct Q-dependence, which indicates specific microstructural changes are introduced by each RE-dopant. The data (symbols) can be quantitatively analyzed by a mass-fractal model (solid curves).[8,9] From a least-squares fit, the mean particle size of the Nd-doped, Ce-doped and pure zirconia are estimated to be $6.56,20.6$, and $22.8 \mathrm{~nm}$, respectively. The particle-size distribution, in terms of the standard deviation of a log-normal distribution, are 1.17, 1.44 and 1.49 , respectively. A standard deviation of unity implies a perfectly uniform size distribution (monodispersity). This result indicates that doping $\mathrm{Nd}(\mathrm{III})$ ions in $\mathrm{ZrO}_{2}$ is more effective in preserving the small, relatively uniform particle size and the large surface area of the powder. This in part is due to the larger ionic radius of $\mathrm{Nd}^{3+}(0.112 \mathrm{~nm})$ than that of $\mathrm{Ce}^{4+}(0.098 \mathrm{~nm})$ and $\mathrm{Zr}^{4+}(0.084 \mathrm{~nm})$ which hinders diffusion of atoms from sintering into larger particles. The slope of the curve over the Porod regime (the high-Q region indicated by the straight lines) provides a measure of the surface roughness of the constituent particles in an aggregate. A slope of -4 indicates smooth surface and a value between -3 and -4 implies rough fractal-like surface. It can be seen from Figs. 1 that the slope for the pure zirconia sample is approaching -4 . Therefore, without RE dopant, a pure zirconia powder is susceptive to sintering to form larger and smoother particles.[10]

The crystal structure of nanophase $\mathrm{CeO}_{2} \cdot \mathrm{ZrO}_{2}$ solid solutions

Pure $\mathrm{ZrO}_{2}$ has three polymorphs: a cubic fluorite structure (space group $\mathrm{Fm} 3 \mathrm{~m}$ ) above $2640 \mathrm{~K}$, a tetragonal structure ( $\mathrm{P} 4_{2} / \mathrm{nmc}$ ) between 1400 and $2640 \mathrm{~K}$, and a monoclinic structure ( $\left.\mathrm{P} 2_{1} / \mathrm{c}\right)$ 
below $1400 \mathrm{~K}$. Our previous studies showed that a small amount of rare-earth solutes (e.g., $\sim 10$ mol\% $\mathrm{La}, \mathrm{Ce}$, and $\mathrm{Nd}$ ) in nanophase zirconia powders can stabilize the tetragonal and cubic phases over a wide range of temperatures.[11] We studied the crystal structures of $\mathrm{Ce}_{x} \mathrm{Zr}_{1 . x} \mathrm{O}_{2}(0$ $\leq x \leq 1.0)$ that were prepared by the coprecipitation method. Fig. 2 shows the neutron powder diffraction profiles and the Rietveld refinements for $x=0.2,0.6$ and 1.0. The structural refinements indicate that the $\mathrm{x}=0.2$ sample is a solid solution containing a major tetragonal phase ( $71 \mathrm{~mol} \%)$ and a minor monoclinic phase $(\sim 29 \mathrm{~mol} \%)$. The sample of pure ceria $(x=1.0)$ shows a cubic fluorite phase. However, in the $0.2<x<0.8$ compositions, the diffraction peak profiles exhibit large intrinsic widths and an additional Lorentzian-like components which are characteristic of small crystalline grains and possibly defect structure. Preliminary Reitveld analysis indicates that the samples contain a mixture of major tetragonal and minor cubic and monoclinic phases. The lattice parameters (tetragonal phase) increase with increasing $\mathrm{Ce}$ concentration as expected from the larger $\mathrm{Ce}^{4+}$ ionic radius.

The crystal structures and phase transformations in the $\mathrm{CeO}_{2} \cdot \mathrm{ZrO}_{2}$ binary system have been investigated by many workers.[12-25] However, we are not aware of any systematic study of the crystal phases of nanostructured $\mathrm{CeO}_{2} \cdot \mathrm{ZrO}_{2}$ powders prepared by low-temperature methods. Yoshima and co-workers $[16,17]$ studied two types of $\mathrm{CeO}_{2} \cdot \mathrm{ZrO}_{2}$ samples prepared by solid-state reaction: the oxygen-deficient samples obtained from quenching the specimens at $1760^{\circ} \mathrm{C}$ in water and the oxygen-restored samples obtained from annealing the quenched specimens in air at $627^{\circ} \mathrm{C}$. They found the high-temperature cubic phase can be retained in the quenched, oxygen-deficient samples whereas in the oxygen-restored samples the tetragonal phase 
is formed for $30-65 \mathrm{~mol} \% \mathrm{CeO}_{2}$ composition and mixed tetragonal and cubic phases for $70-90$ mol\% $\mathrm{CeO}_{2}$. Meriani and co-workers $[23,24]$ observed a single-phase of tetragonal symmetry in non-quenching samples containing $40-60 \mathrm{~mol}^{2} \mathrm{CeO}_{2}$ and mixed phases in both the low and high $\mathrm{CeO}_{2}$-content samples. Although the different synthesis methods do not warrant a direct comparison of the crystal structures of the present samples with those found by other authors, accumulative evidence supports the formation of a predominant tetragonal phase of $\mathrm{Ce}_{x} \mathrm{Zr}_{1-x} \mathrm{O}_{2}$ for intermediate range of $\mathrm{CeO}_{2}$ content. The detailed structural analysis of our samples over the entire composition range will be discussed in a later paper. Here we discuss the redox reactions in the $\mathrm{x}=0.2$ (mainly tetragonal) and the $\mathrm{x}=1.0$ (cubic) samples studied by in-situ diffraction experiments.

The redox reaction of $\mathrm{Ce}$ ions in $\mathrm{CeO}_{2} \cdot \mathrm{ZrO}_{2}$ three-way catalysts

Major pollutants (e.g, $\mathrm{CO}, \mathrm{HC}$, and Nox) from automobiles are generated from incomplete combustion of gasoline and from the reaction of nitrogen with oxygen in the cylinder at combustion temperature. The chemical reactions involved in the simultaneous reduction and oxidation of these pollutants during the catalyst operation are: $2 \mathrm{CO}+\mathrm{O}_{2} \rightarrow 2 \mathrm{CO}_{2}, 2 \mathrm{HC}+3 \mathrm{O}_{2}$ $\rightarrow 2 \mathrm{CO}_{2}+\mathrm{H}_{2} \mathrm{O}, 2 \mathrm{CO}+2 \mathrm{NO} \rightarrow 2 \mathrm{CO}_{2}+\mathrm{N}_{2}, 4 \mathrm{HC}+10 \mathrm{NO} \rightarrow 4 \mathrm{CO}_{2}+2 \mathrm{H}_{2} \mathrm{O}+5 \mathrm{~N}_{2}$. The success of the TWC relies on the control of the air-to-fuel mass ratio (A/F) to within a narrow window during the dynamic driving condition. This is achieved by the employment of oxygen sensors (which consist of rare-earth doped zirconia electrolytes) in the exhaust stream in conjunction with a feedback control logic of the engine. However, a time lag between the sensor-signal processing and the $\mathrm{A} / \mathrm{F}$ adjustment leads to an alternating (fuel) rich-lean deviation from the 
optimal stoichiometric $\mathrm{A} / \mathrm{F}$ ratio. Owing to the low redox potential of non-stoichiometric $\mathrm{CeO}_{2}$, oxygen release and intake resulting from conversion between the $3+$ and $4+$ oxidation states of the Ce ions in the oxide provide the oxygen storage capability (OSC) that are essential to the effective catalytic function under the fluctuating $\mathrm{A} / \mathrm{F}$ environment.

It is well known that $\mathrm{Ce}^{4+}$ ions in $\mathrm{Ce}_{\mathrm{x}} \mathrm{Zr}_{1-\mathrm{x}} \mathrm{O}_{2}$ can be reduced to $\mathrm{Ce}^{3+}$ state, creating oxygen vacancies to form $\mathrm{Ce}^{4+}{ }_{x-2 y} \mathrm{Ce}^{3+}{ }_{2 y} \mathrm{Zr}_{1-x} \mathrm{O}_{2-y}$.[2] However, in pure $\mathrm{CeO}_{2} \cdot \mathrm{ZrO}_{2}$ the reduction occurs mainly on the surface region at high temperatures. For example, Zhu and co-workers[25] observed the phase separation in a $12 \mathrm{~mol} \% \mathrm{CeO}_{2}-\mathrm{ZrO}_{2}$ ceramic induced by $\mathrm{Ce}^{4+} \rightarrow \mathrm{Ce}^{3+}$ conversion at temperatures above $1000^{\circ} \mathrm{C}$. In practice, however, the redox removal reaction can be facile if well-dispersed or high surface-area $\mathrm{CeO}_{2}-\mathrm{ZrO}_{2}$ complex oxides are used with $\mathrm{Pt}$ or $\mathrm{Rh}$ based TWCs. [26]

An understanding of the metal-support interactions in TWCs such as the $\mathrm{Ce}_{\mathrm{x}} \mathrm{Zr}_{1-\mathrm{x}} \mathrm{O}_{2-\mathrm{y}} / \mathrm{Pt}$ system is paramount to the design and development of better air-pollution control catalysts. Harrison and co-workers[27] provided a model for the metal-ceria interaction during the oxidation of $\mathrm{CO}$, which is shown in Fig. 3. It involves the initial adsorption of $\mathrm{CO}$ molecules on Pt atoms and subsequently a reduction of $\mathrm{Ce}$ cations in the Ceria/Pt interface. The $\mathrm{Ce}^{4+} \rightarrow \mathrm{Ce}^{3+}$ conversion releases oxygen atoms from ceria for the oxidation of $\mathrm{CO}$ to $\mathrm{CO}_{2}$ which subsequently desorbs from the metal, leaving vacancies on the surface of the oxide particles. In order to sustain the redox reaction, the vacant sites have to be filled by oxygen from the lattice through atomic diffusion. Many aspects of the proposed mechanisms are still not understood. We are interested in the response to the redox process in the oxide lattice. Similar mechanisms for the redox 
reaction and oxygen-vacancy diffusion in $\mathrm{CeO}_{2} \cdot \mathrm{ZrO}_{2}$ systems have been given by other workers.[28]

Since neutrons probe the bulk of a sample rather than the surface, and the technique is sensitive to light atoms (e.g., O), it is useful to monitor the effects of oxygen or oxygen-vacancy diffusion on the structural modification under a typical catalytic operation such as redox reactions. This requires experiments undertaken in a sample environment that simulates the reaction chamber of practical OSC reactions. By virtue of the substantial difference in the ionic radius of $\mathrm{Ce}^{4+}(0.097$ $\mathrm{nm})$ and $\mathrm{Ce}^{3+}(0.114 \mathrm{~nm})$, which permits the manifestation of the redox process via changes in the unit-cell volume of the lattice, we carried out in-situ neutron diffraction on $\mathrm{Ce}_{\mathrm{x}} \mathrm{Zr}_{1-\mathrm{x}} \mathrm{O}_{2-\mathrm{y}}$ with and without impregnated $\mathrm{Pt}(1 \mathrm{wt} \%)$ at high temperatures under oxidizing and reducing atmospheres. Diffraction data at each temperature were collected in the following manner for both samples: heating from $25^{\circ}$ to $400^{\circ} \mathrm{C}$ in flowing $2 \% \mathrm{O}_{2}$ balanced by $\mathrm{Ar}$ gas followed by continued heating from $400^{\circ}$ to $700^{\circ} \mathrm{C}$ in flowing $1 \% \mathrm{CO}$ balanced by $\mathrm{Ar}$. The temperature was stepped at an interval of $50^{\circ} \mathrm{C}$ and a 20 -min wait prior to the $1 \mathrm{~h}$-data collection was allowed for thermal equilibration at each temperature. At selected temperatures between $400^{\circ}$ and $800^{\circ} \mathrm{C}$ multiple $30 \mathrm{~m}$-data sets were collected. Fig. 4 shows the temperature and atmosphere dependence of the unit-cell volume of the tetragonal phase of $\mathrm{Ce}_{0.2} \mathrm{Zr}_{0.8} \mathrm{O}_{2-\mathrm{y}}$ and the cubic phase of $\mathrm{CeO}_{2-\mathrm{y}}$ samples with and without dispersed Pt. First, under an oxidizing atmosphere $\left(2 \% \mathrm{O}_{2} / \mathrm{Ar}\right)$ up to $400^{\circ} \mathrm{C}$ the lattice unit cell of the Pt impregnated materials is slight larger than those without $\mathrm{Pt}$. Second, as the gas is switched to a reducing atmosphere ( $1 \% \mathrm{CO} / \mathrm{Ar})$, the lattice expands at a constant temperature, as it can be seen from the multiple data points collected over $1-4 \mathrm{~h}$ periods 
at $400^{\circ}, 500^{\circ}, 600^{\circ}$ and $800^{\circ} \mathrm{C}$. Third, the expansion occurs at a much higher rate in the samples containing Pt. Similar phenomenon was also observed in other $\mathrm{Ce}_{\mathrm{x}} \mathrm{Zr}_{1-\mathrm{x}} \mathrm{O}_{2-\mathrm{y}} / \mathrm{Pt}$ samples. The occurrence of anomalous thermal expansion only in a reducing atmosphere confirms the gradual conversion of the $\mathrm{Ce}^{4+}$ to larger $\mathrm{Ce}^{3+}$ ions. Since the observed d-spacing reflects the long-range order structure in the crystalline grains, the enhanced expansion in Pt-containing samples implies the migration of oxygen vacancies from the interfacial region between the oxide and Pt particles to the bulk of the oxide lattice. In samples contain no active metal component, on the other hand, the redox reaction and the generation of oxygen vacancies are limited mainly on the surface of the oxide grains. High activity requires heat treatments at higher temperatures (above $\sim 700^{\circ} \mathrm{C}$, see

Fig. 4). Therefore, the neutron results support the model for metal-support interaction proposed by Harrison and co-workers.[27]

\section{Conclusion}

We demonstrate the usefulness of neutron-scattering method in the characterization of the structural modification of high-surface-area zirconia powder by rare-earth doping. First, the growth of primary particles from hydrolysis or coprecipitation in $\mathrm{ZrOCl}_{2}$ aqueous solutions, and the microstructural evolution due to annealing the obtained pure and $\mathrm{R}$-modified $\mathrm{ZrO}_{2}$ powders can be studied by small-angle scattering.[10,29] Second, through powder diffraction the formation of crystal phases depending on the composition in nanophase (coprecipitated) $\mathrm{CeO}_{2}$ $\mathrm{ZrO}_{2}$ as well as $\mathrm{RE}(\mathrm{III})$-doped $\mathrm{ZrO}_{2}$ can be characterized. [11] Third, the dynamics of hydrogen atoms associated with the surface hydroxyl groups and adsorbed water molecules on RE-

modified $\mathrm{ZrO}_{2}$ over a frequency range of $0-4400 \mathrm{~cm}^{-1}$ can be investigated by inelastic scattering. 
Details of these experiments are given elsewhere. [30, 31] Finally, we emphasize the importance of in-situ scattering experiments under controlled atmospheres and at high temperatures for the understanding of redox reaction involving Ce ions.[32, 33] Here, we presented the recent neutron-diffraction results concerning other compositions of $\mathrm{CeO}_{2}-\mathrm{ZrO}_{2}$. Currently, we continue our investigations over the full range of ceria composition in the $\mathrm{CeO}_{2} \cdot \mathrm{ZrO}_{2}$ system, and extend the studies to zirconias prepared by sol-gel and microemulsion methods. Nanostructured zirconias prepared by these low-temperature processes can in principle provide much higher catalytic activity. In the climate of increasing public awareness and concern of environmental issues, the demand for better catalysts to cope with governmental regulations and industrial needs becomes imperative. Research of RE elements in catalytic applications by combining neutron scattering with other methods is expected to expand rapidly in the future.

Acknowledgment

We are indebted to our colleagues. L. E. Iton, J. W. Richardson, Jr., S. M. Short, S. Suzuki, and P. Thiyagarajan for their help in these studies. Work performed at Argonne National Laboratory is supported by the U. S. DOE-BES under Contract No. W31-109-ENG-38. 


\section{References:}

1. B. J. Cooper, Platinum Metals Rev. 38, 2 (1994).

2. A. Trovarelli, Catal. Rev. - Sci. Eng. 38, 439 (1996).

3. J. Barbier, Jr. and D. Duprez, Appl. Catalysis B 4, 105 (1994).

4. M. Ozawa and M. Kimura, J. Less-Common Metals 171, 195 (1991).

5. C. F. Baes, Jr. and R. E. Mesmer, The hydrolysis of cations (John Wiley \& Sons, New York, 1976).

6. A. Bleier and R. M. Cannon, Mat. Res. Soc. Symp. Proc. 73, 71 (1986).

7. A. Singhal, L. M. Toth, J. S. Lin, and K. Afholter, J. Am. Ceram. Soc. 118, 11529 (1996).

8. S. K. Sinha, Physica D 38, 310 (1989).

9. J. Teixeira, J. Appl. Cryst. 21, 781 (1988).

10. C.-K. Loong, P. Thiyagarajan, J. Richardson, J. W., M. Ozawa, and S. Suzuki, J. Catal. 171, 498 (1997).

11. C.-K. Loong, J. W. Richardson, Jr., and M. Ozawa, J. Catal. 157, 636 (1995).

12. E. Tani, M. Toshimura, and S. Somiya, J. Am. Ceram. Soc. 66, 506 (1983).

13. E. Tani, M. Yoshimura, and S. Somiya, J. Am. Ceram. Soc. 66, 11 (1983).

14. P. Duwez, F. Odell, and F. H. Brown, Jr., J. Am. Ceram. Soc. 35, 107 (1952).

15. M. Yashima, N. Ishizawa, and M. Yoshimura, J. Am. Ceram. Soc. 75, 1550 (1992). 
16. M. Yashima, K. Morimoto, N. Ishizawa, and M. Yoshimura, J. Am. Ceram. Soc. 76, 1745 (1993).

17. M. Yashima, K. Morimoto, N. Ishizawa, and M. Yoshimura, J. Am. Ceram. Soc. 76, 2865 (1993).

18. M. Yashima, H. Arashi, M. Kakihana, and M. Yoshimura, J. Am. Ceram. Soc. 77, 1067 (1994).

19. M. Yashima, T. Mitsuhashi, H. Takashina, M. Kakihana, T. Ikegami, and M. Yoshimura, J. Am. Ceram. Soc. 78, 2225 (1995).

20. M. Yashima, S. Sasaki, Y. Yamaguchi, M. Kakihana, M. Yoshimura, and T. Mori, Appl. Phys. Lett. 72, 182 (1998).

21. S. Meriani, Thermo. Acta 58, 253 (1982).

22. S. Meriani, Mat. Sci. Engin. 71, 369 (1985).

23. S. Meriani and G. Spinolo, Powder Diffr. 2, 255 (1987).

24. S. Meriani, Mat. Sci. Engin. A109, 121 (1989).

25. H.-Y. Zhu, T. Hirata, and Y. Muramatsu, J. Am. Ceram. Soc. 75, 2843 (1992).

26. M. Ozawa, M. Kimura, and A.Isogai, J. Alloys Compounds 193, 73 (1993).

27. B. Harrison, A. F. Diwell, and C. Hallett, Platinum Metals Rev. 32, 73 (1988).

28. M. G. Sanchez and J. L. Gazquez, J. Catal. 104, 120 (1987).

29. M. Ozawa, S. Suzuki, C.-K. Loong, and P. Thiyagarajan, J. Mat. Sci. Lett. 16, 1360 (1997).

30. C.-K. Loong, L. E. Iton, and M. Ozawa, Physica B 213 \& 214, 640 (1995). 
31. C.-K. Loong, F. Trouw, M. Ozawa, and G. Zuzuki, in Materials Research Using Cold Neutrons at Pulsed Sources, edited by P. Thiyagarajan, F. Trouw, C.-K. Loong and M. A. Marzec (World Scientific, Argonne National Laboratory, Argonne, IL, 1997), p. submitted.

32. C.-K. Loong, S. M. Short, M. Ozawa, and S. Suzuki, Mat. Res. Soc. Symp. Proc. 497, in press (1998).

33. M. Ozawa and C.-K. Loong, Catal. Today 50, 329 (1998). 


\section{Figure Captions:}

Figure 1. The log-log plot of SANS intensity versus $\mathrm{Q}$ for $\mathrm{Nd}_{0.1} \mathrm{Zr}_{0.9} \mathrm{O}_{1.95}, \mathrm{Ce}_{0.1} \mathrm{Zr}_{0.9} \mathrm{O}_{1.95}$ and $\mathrm{ZrO}_{2}$ that were heat-treated at $600^{\circ} \mathrm{C}$. Typical errors are of the size of the symbols except for $\mathrm{Q}>$

$0.1 \AA^{-1}$ where errors are large. The solid lines represent the fits of the data to the fractal model.

Limiting slopes for power-law behavior are given by the dotted lines.

Figure 2. Typical Rietveld profile fits in the $0.05-0.35 \mathrm{~nm}$ region of $\mathrm{d}$-spacing for the $\mathrm{Ce}_{\mathrm{x}} \mathrm{Zr}_{1-\mathrm{x}} \mathrm{O}_{2}$ powders under a flowing $2 \% \mathrm{O}_{2} / \mathrm{Ar}$ gas environment at low temperatures (below $200^{\circ} \mathrm{C}$ ). The symbols are the observed, background subtracted intensities. The solid line represents the calculated crystalline intensities. For the $\mathrm{x}=0.2$ and 0.6 samples, the tick marks indicate the positions of the Bragg reflections of the monoclinic (top row) and tetragonal (bottom row) phases. $\mathrm{CeO}_{2}(\mathrm{x}=1.0)$ contains solely the cubic phase of fluorite structure.

Figure 3. A schematic model for oxidation of $\mathrm{CO}$ by a $\mathrm{CeO}_{2} \cdot \mathrm{ZrO}_{2} / \mathrm{Pt}$ catalyst promoted by metaloxide support interaction (after Ref. 27).

Figure 4. The temperature and atmosphere dependence of the unit-cell volume of tetragonal $\mathrm{Ce}_{0.2} \mathrm{Zr}_{0.8} \mathrm{O}_{2-\mathrm{y}}$ (left) and $\mathrm{CeO}_{2-\mathrm{y}}$ (right) with (open symbols) and without (solid symbols) Ptimpregnation. The samples were first heated in $2 \% \mathrm{O}_{2} / \mathrm{Ar}$ (circles) and then switched to $1 \% \mathrm{CO} / \mathrm{Ar}$ and continued heating to 700 or $800^{\circ} \mathrm{C}$ (diamonds). Data were collected at each temperature for $1 \mathrm{~h}$ except at $400^{\circ}, 500^{\circ}, 600^{\circ}, 700^{\circ}$ and $800^{\circ} \mathrm{C}$ multiple data sets were recorded every $0.5 \mathrm{~h}$. Uncertainties of the data points are comparable to the size of the symbols. 


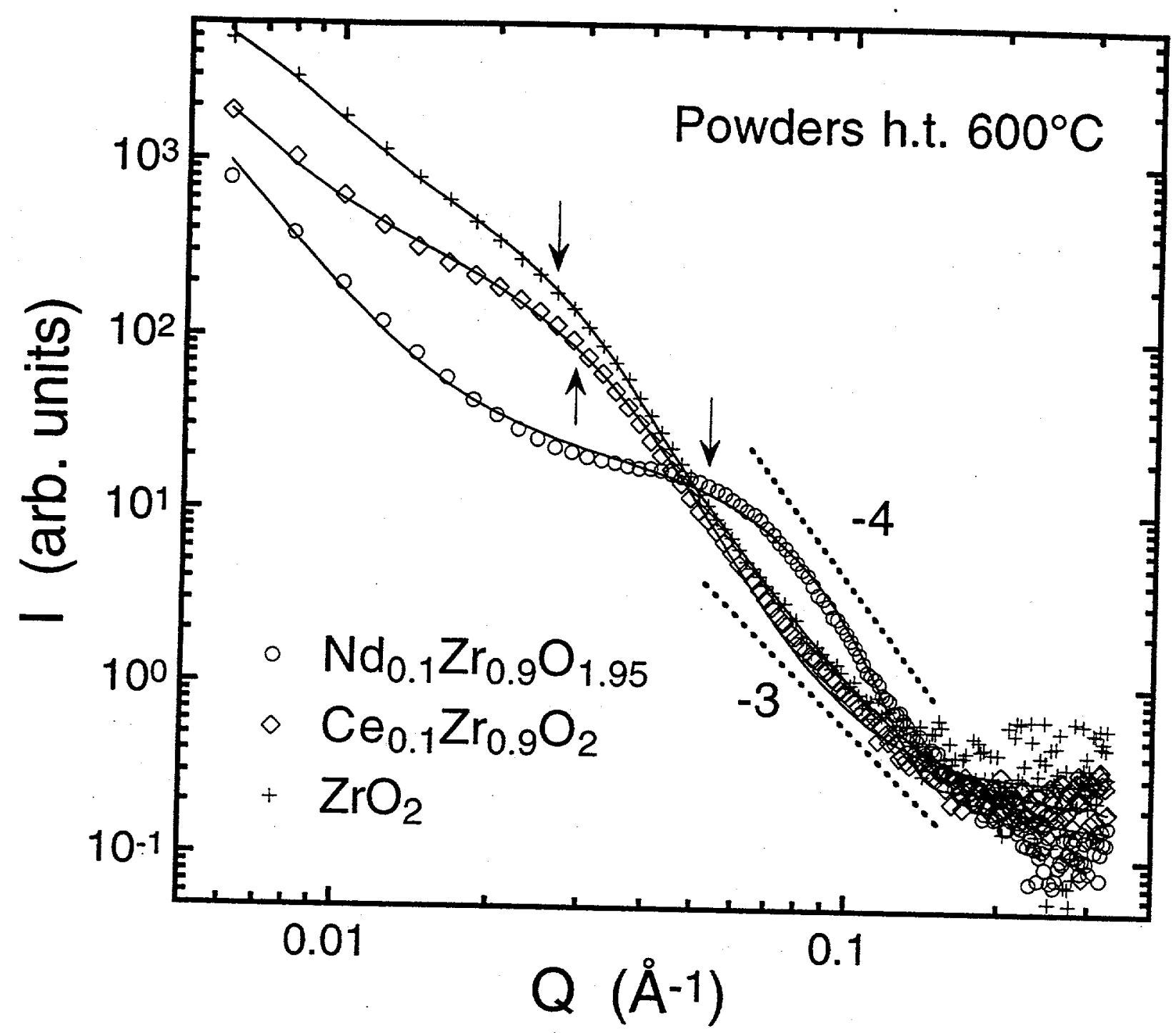

Fig. 1, Loong and Ozawa, "The role of rare-earth dopants in ..." 


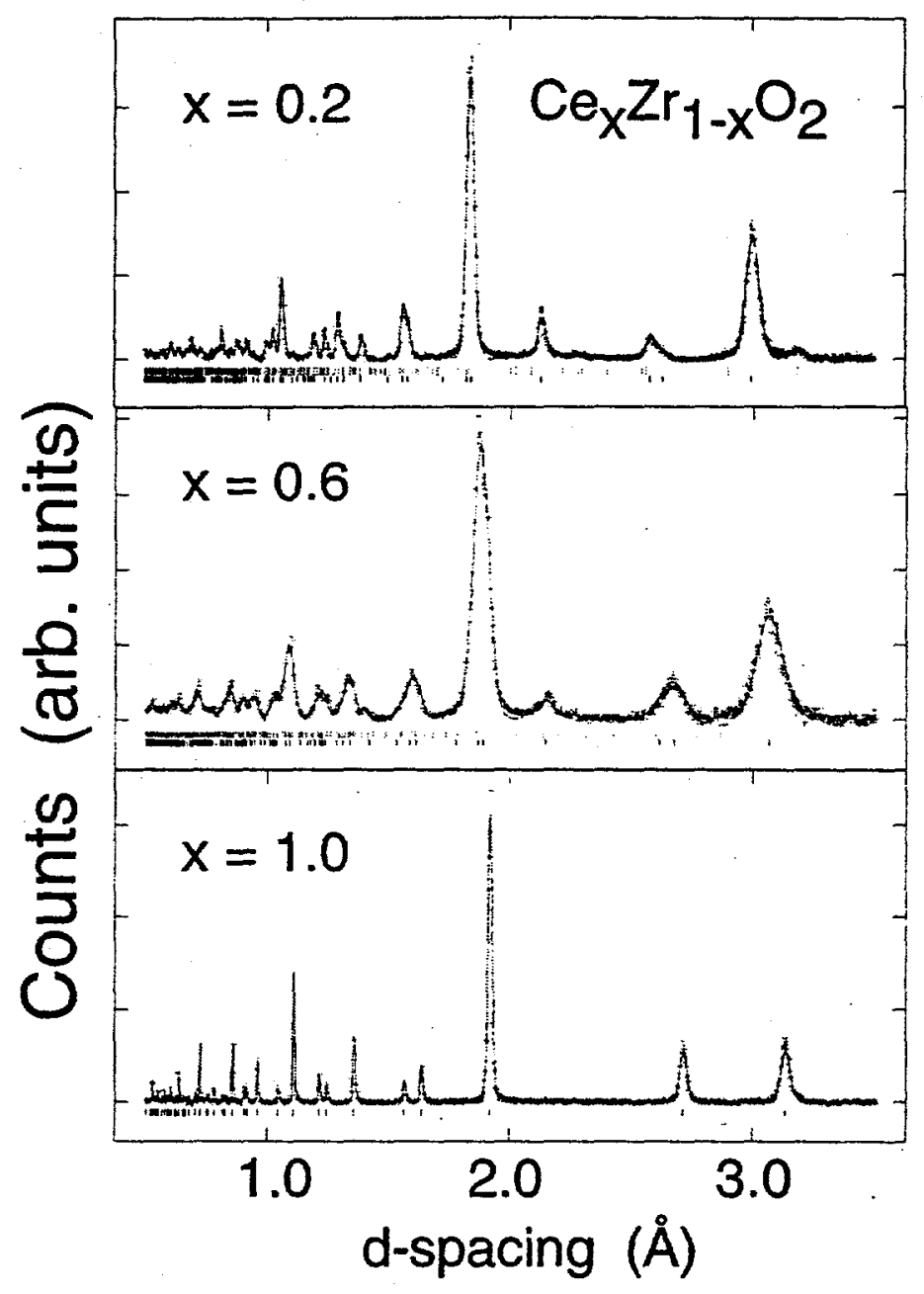

Fig. 2, Loong and Ozawa, "The role of rare-earth dopants in..." 


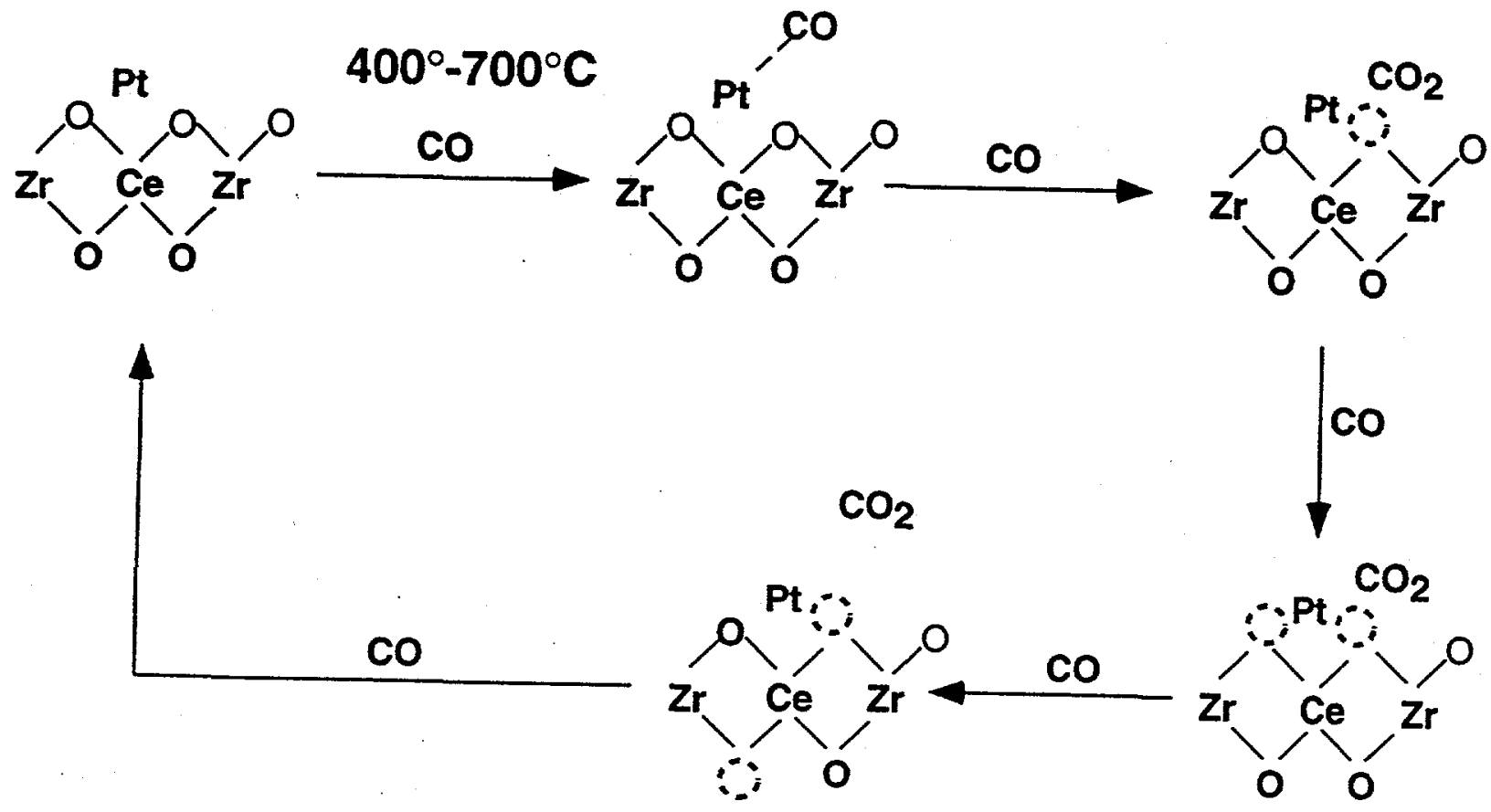

Fig. 3. Loong and Ozawa, "The role of rare-earth dopants in..." 


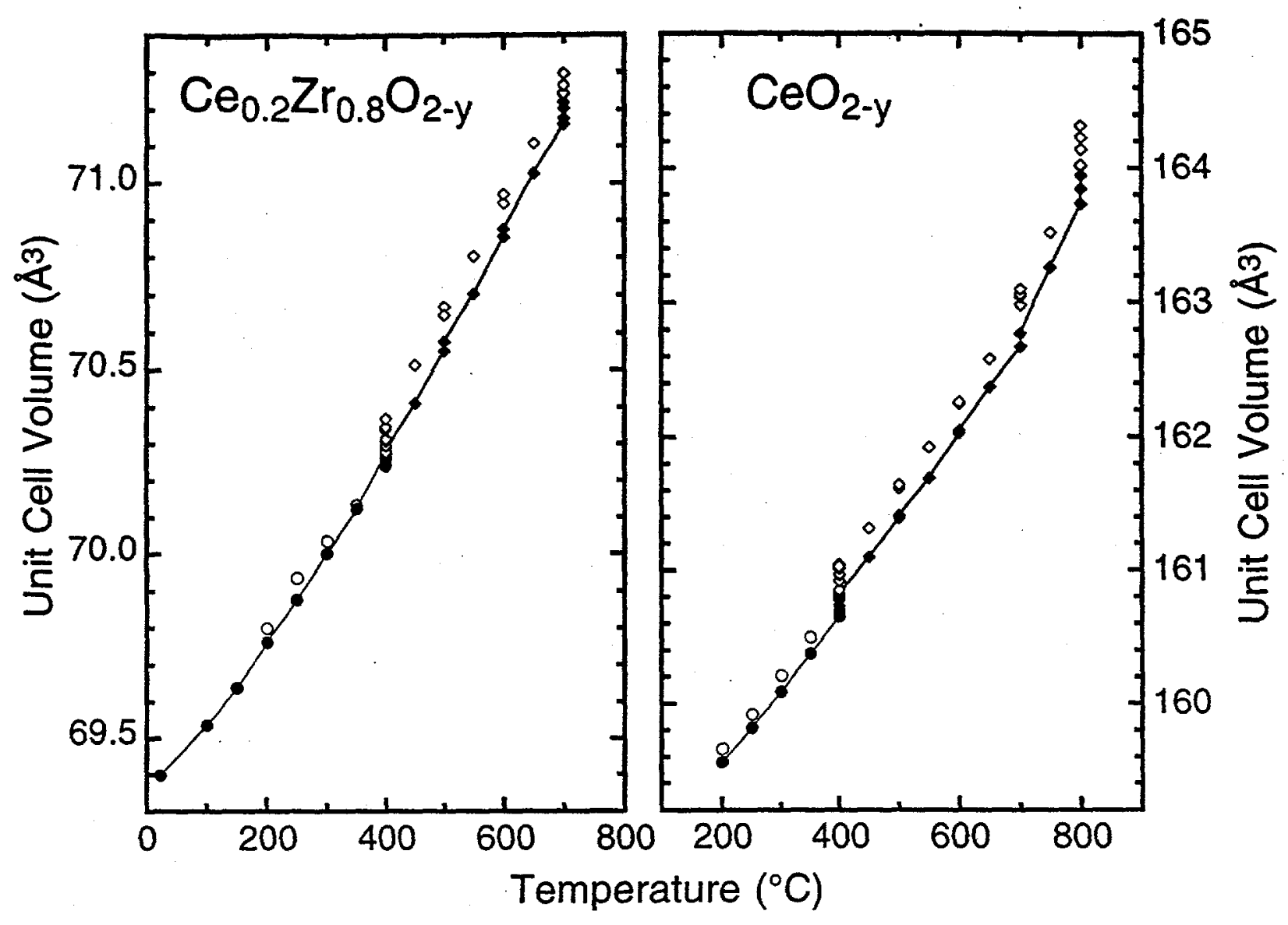

Fig. 4, Loong \& Ozawa, "The role of rare-earth dopants in ..." 